\title{
Investigation on Lateral Loading on Masonry Walls
}

\author{
Hari Ram Parajuli ${ }^{1}$ and Arjun Ghimire ${ }^{2}$ \\ ${ }^{1}$ National Reconstruction Authority, Kathmandu, Nepal \\ ${ }^{2}$ Department of Civil Engineering, Thapathali Campus, Institute of Engineering, \\ Tribhuvan University, Nepal
}

\section{*CORRESPONDENCE:}

\section{Hari Parajuli}

National Reconstruction Authority,

Kathmandu, Nepal

Email: hariparajuli@ioe.edu.np.
ISSN : 2382-5359(Online), 1994-1412(Print)

DOI:

https://doi.org/10.3126/njst.v20i1.39385

\section{ACCESS THE ARTICLE ONLINE}

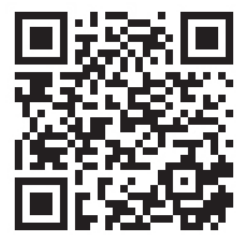

\section{CONFILICT OF INTEREST: None}

Copyright: The Author(s) 2020. This is an open access article under the $\underline{\mathrm{CC} \text { BY license. }}$

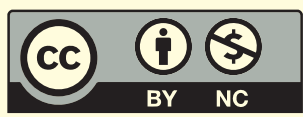

\begin{abstract}
Though a traditional material used for construction for ages, masonry is a complex composite material, and its mechanical behavior is influenced by a large number of factors, is not generally well understood. This research aims to study the methodology available in the literature to evaluate the increase in performance of masonry by applying different reinforcement options under in-plane lateral loading. Nonlinear static analysis has been carried out as part of this research to achieve the above objectives. Different unreinforced masonry wall panels were analyzed at various load conditions. Material properties for the masonry wall were taken from the experimental test results of previous literature. The walls were first checked for two failure mechanisms. The stress distributions of walls were checked in each step of analysis and shear failure, and rocking failure was found. Each wall was then analyzed for six different reinforcement options. The comparison of results obtained from the reinforced wall analysis with that of the unreinforced wall indicated significant increase in lateral load-bearing capacity and decreased wall displacement with reinforcement. The maximum increase in load-bearing capacity was achieved by adding chicken wire mesh or CFRP bands throughout the wall while the maximum decrease in displacement was achieved by adding $12 \mathrm{~mm}$ diameter bars at the spacing of one meter.
\end{abstract}

Keywords: Lateral loading, CFRP, gorkha earthquake

\section{INTRODUCTION}

Masonry is one of the most commonly used and essential construction materials around the world. Despite this, nowadays, there is a lack of information and research to characterize its mechanical properties and structural performance. The problems to adequately defined masonry's mechanical properties are related to finding the elements failure pattern which are similar everywhere. Thus, the input parameters to define masonry's mechanical properties are vast, and its properties are many and various. Nepal has experienced several great earthquakes in different periods, including a recent Gorkha Earthquake 2015 (Parajuli 2012). Most of the masonry buildings built in Nepal are not built according to the code requirements. Such buildings, when subjected to the earthquake, may not resist the seismic loads coming into them. So, it is necessary to check the seismic efficiency of buildings by analyzing their seismic performance in the existing condition. 


\subsection{Objectives}

Engineers and researchers have adopted an elastic analysis for Masonry's structural behavior using somewhat arbitrary elastic parameters and strengths of Masonry. Such analyses can give wrong and misleading results. The effect of nonlinearity on the masonry model's behaviour is very significant and must be accurately taken into account in analyzing masonry structures' ultimate behaviour. This study is carried to find out the behaviour of unreinforced Masonry, considering the effect of nonlinearity.

This study's primary objective is to determine the behaviour of unreinforced masonry walls by performing numerical modelling of existing and retrofitted masonry building walls subjected to lateral in-plane loading, which requires the following specific objectives.

i. To determine the increase in performance of the masonry wall by using different types of skin retrofit options.

ii. To compare the performance of skin retrofit options.

\section{MATERIALS AND METHODS}

\subsection{Analytical Process and Numerical Modelling}

In this study, three walls of three different buildings are taken based on possible failure mechanisms governed by the following equations and described below (Parajuli et al. 2011).The wall with chicken wire mesh and CFRP mesh was modelled as equivalent one unit rather than individual element which behaves different than masonry units only. From the studies by Yi et al. (2004), Abrams \& Shah (1992), Ghiassi et al. (2004), it is seen that walls with lower aspect ratios (ratio of height to length of a wall) are expected to fail by shear failure mechanism.

Sliding shear strength:

$V_{s}=v_{m e} A_{n}$

$V_{d}=f_{d} A_{n}\left(\frac{l}{h}\right) \sqrt{1+\frac{f_{a}}{f_{d}}}$

Diagonal shear strength:

Rocking strength:

$V_{r}=0.9 \alpha P\left(\frac{l}{h}\right)$

As a failure mechanism (Pandey et al. 2004) also depends upon vertical axial stress, studies show that wall having lower vertical axial stress may exhibit sliding shear failure whereas wall with higher vertical axial stress may exhibit diagonal shear failure. Hence, two walls of the single-storey building having an aspect ratio of 0.6 and a thickness of $230 \mathrm{~mm}$ are taken as the model walls named as wall1 and wall ${ }^{2}$. The vertical load of $8 \mathrm{KN} / \mathrm{m}$ and the lateral load of $100 \mathrm{KN}$ were applied at the wall's roof level. The other two-storey building walls having an aspect ratio of 1.71 and thickness of $230 \mathrm{~mm}$ are taken as the model walls named as wall 3 and wall4.Based on the calculation of $25 \mathrm{~cm}$ masonry wall, the vertical load of $8 \mathrm{KN} / \mathrm{m}$ is applied at each floor level, and the lateral load of $200 \mathrm{KN}$ and $100 \mathrm{KN}$ was applied at roof level and floor level of the wall respectively. The basic of selecting loads are making combing failure mechanism with numerical trials (Parajuli 2012). Two storey building walls with an aspect ratio of 0.96 and thickness of $230 \mathrm{~mm}$ are taken as the model walls named as wall5 and wall6 and shown in the appendix. The vertical load of $8 \mathrm{KN} / \mathrm{m}$ is applied at each floor level, and the lateral load of $200 \mathrm{KN}$ and $100 \mathrm{KN}$ was applied at roof level and floor level of the wall respectively. The wall's lateral strength is governed by Equation's minimum values (1) and Equation (3).Each of the walls is analyzed for different reinforcement options given as:

i. Unreinforced Masonry Wall

ii. Wall with $12 \mathrm{~mm}$ diameter reinforcement bars vertically placed at a centre-to-centre distance of $1 \mathrm{~m}$.

iii. Wall with reinforcement as chicken wire mesh of $1 \mathrm{~m}$ width at both sides placed vertically at ends of the wall.

iv. Wall with reinforcement as chicken wire mesh applied at both sides of the wall throughout the wall panel.

v. Wall with reinforcement as four vertical strips of Carbon Fibber Reinforced Polymer (CFRP) mesh with a width of $20 \mathrm{~cm}$ and thickness of $2 \mathrm{~mm}$ applied at both sides of the wall.

vi. Wall with reinforcement as two horizontal and two vertical strips of CFRP mesh with a width of $20 \mathrm{~cm}$ and thickness of $2 \mathrm{~mm}$ applied at both sides of the wall.

vii. Wall with reinforcement as CFRP mesh applied at both sides of the wall throughout wall panel

There are different possibilities to solve the problem of modelling masonry. These alternatives depend on how detailed the modelling is and, consequently, if the model can describe accurately different types of failure. They are micro and macro modeling (Lourenco, 1996). In general, the micro models require more detailed information about the material properties than macro models. This information should be obtained, preferably, from specific 
laboratory tests. In case this type of information is not available, the information should be obtained from the literature. This condition makes micro models harder to implement than macro models. In the present study, the finite element macro modelling technique is used to determine masonry walls' behavior.
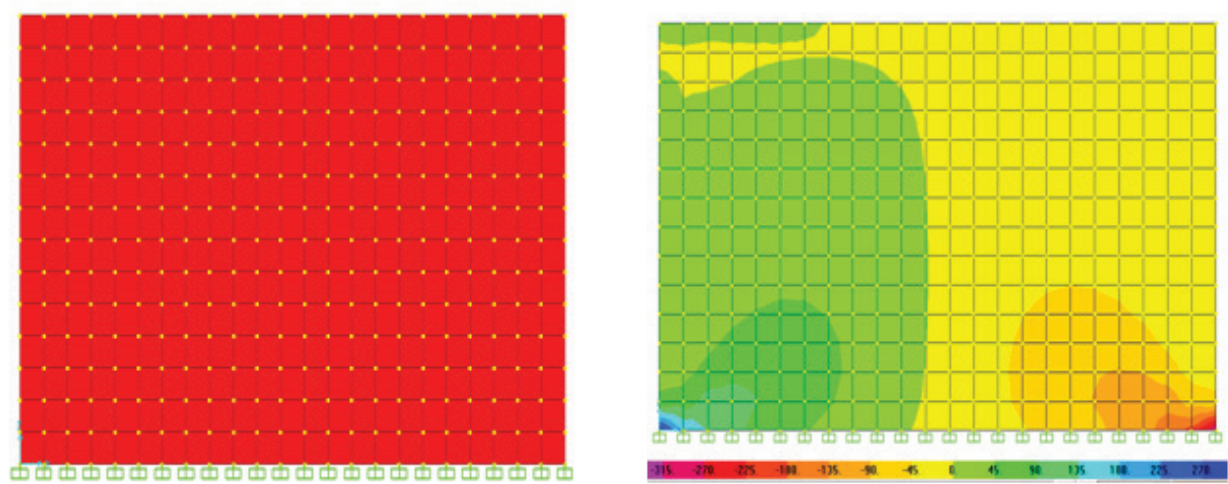

Fig. 1. Wall 1 Model
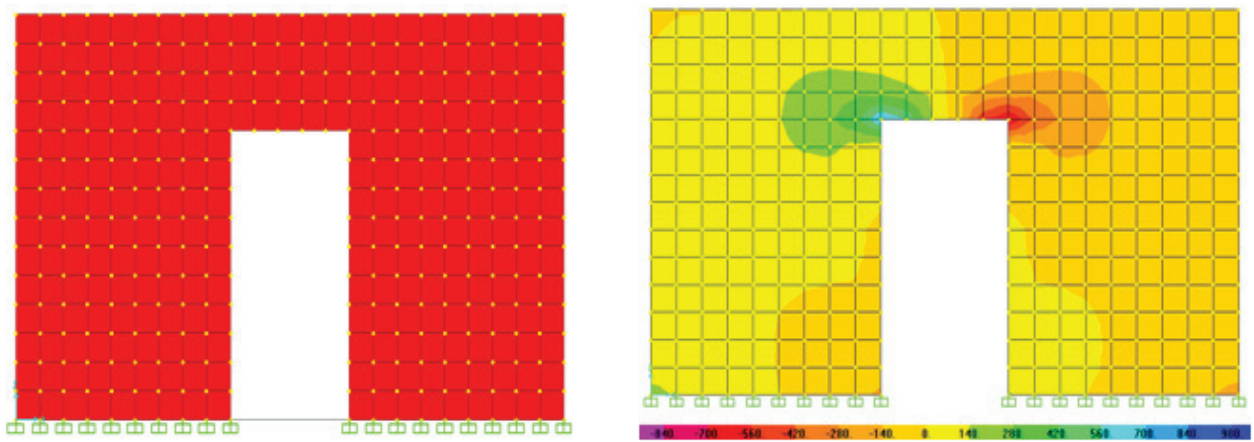

Fig. 2. Wall 2 Model

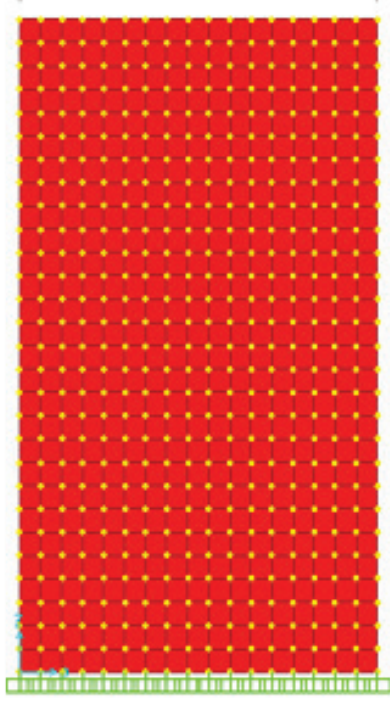

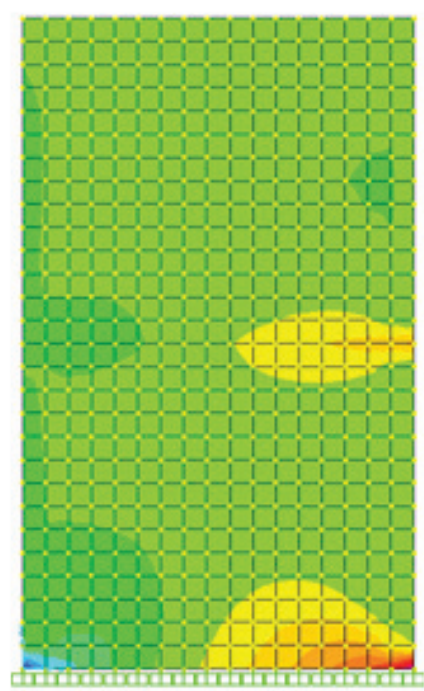

a

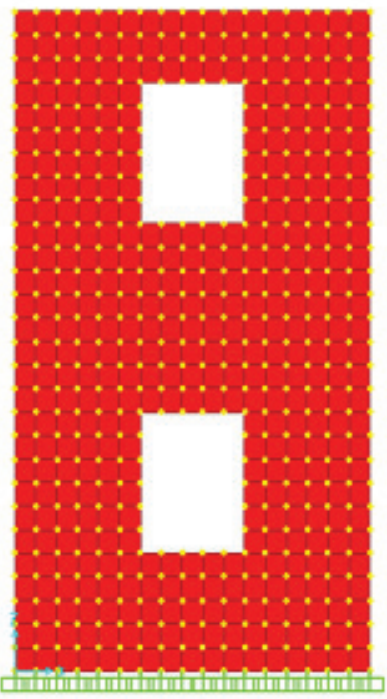

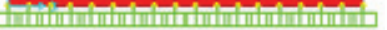

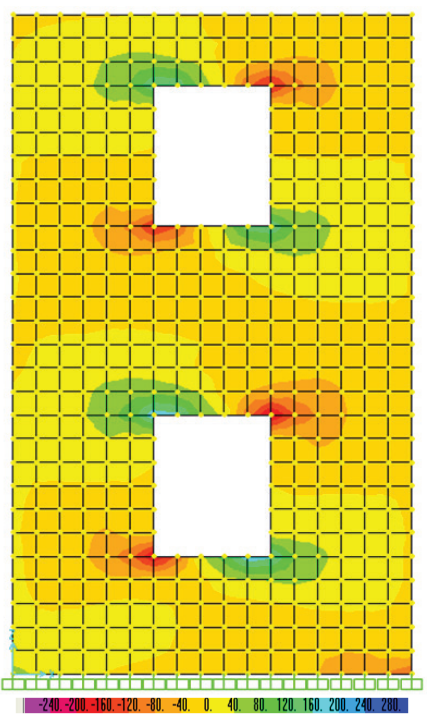

Fig. 3. Wall 3 Model

Fig. 4. Wall 4 Model 

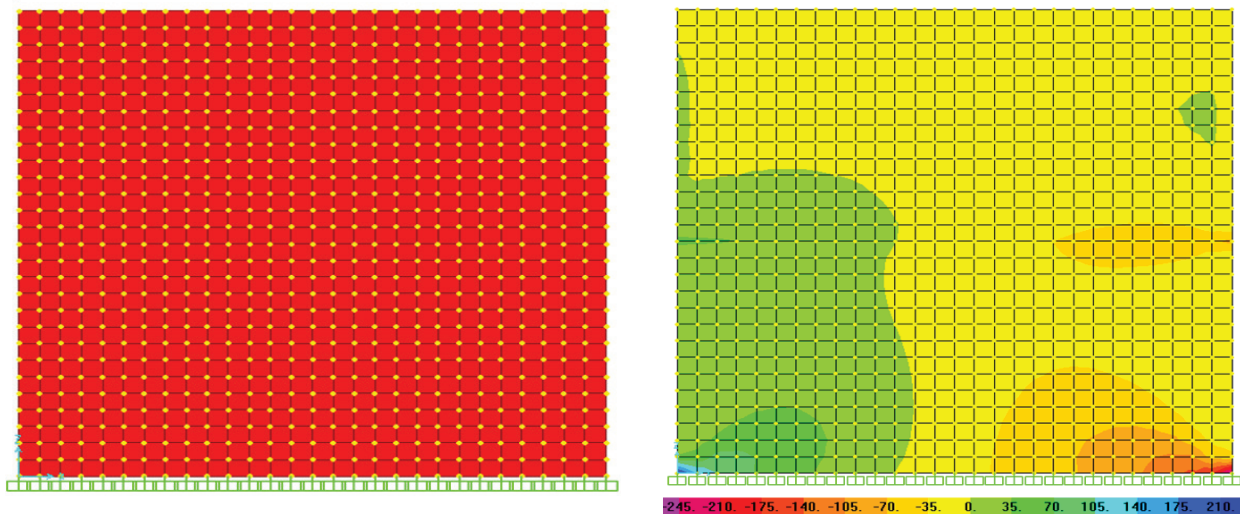

Fig. 5. Wall 5 Model
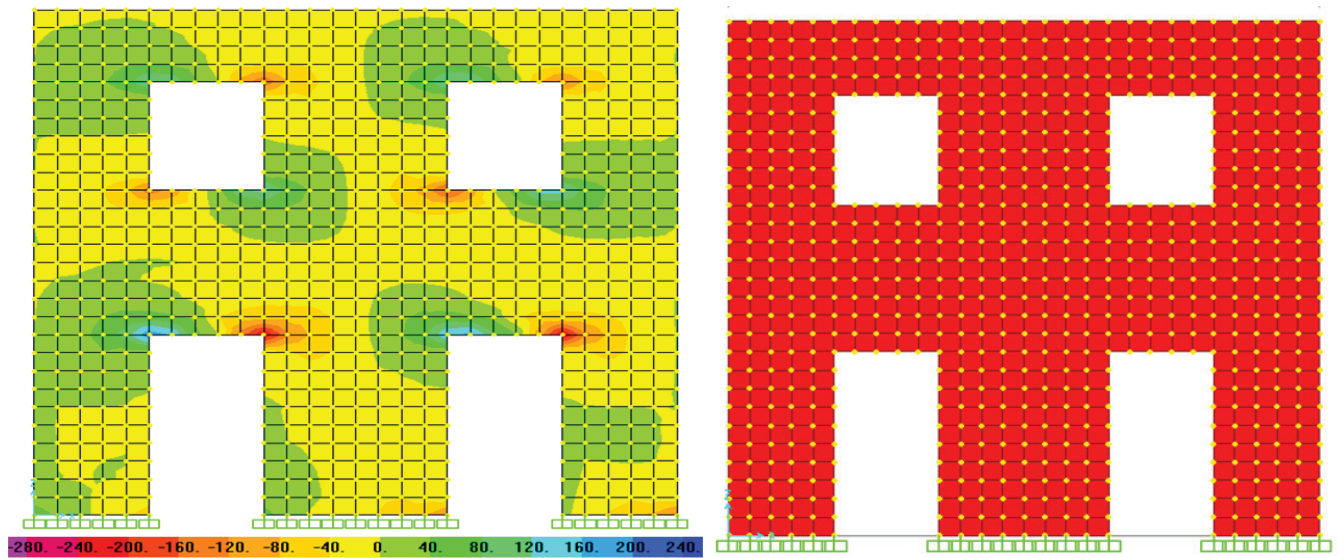

Fig. 6. Wall 6 Model

\section{RESULTS AND DISCUSSIONS}

The masonry panels' behavior shown in Figs 1-6 is analyzed (Pasticier et al. 2007) in this section. The model wall was discretized with triangular plane elements. In the Figs, the contours represent concentration of stresses. For details Ghimire 2016 is referred. As described in the previous section, masonry walls for different failure mechanisms and different reinforcement options are analyzed. Different nonlinear layers in different directions are used to represent the behaviour of Masonry. The thickness of each nonlinear layer is kept equal to the wall thickness and that of reinforcement layer equal to the area of reinforcement divided by the discretized mesh length. Six models representing six types of reinforcement options described in the previous section are prepared for each wall, and pushover analysis has been carried out.

\subsection{Check for Failure Mechanism}

Six wall panels of different aspect ratios and opening conditions were taken, and the calculation of their rocking and sliding shear strength was done (Table 1). Each pier's strength in every storey is calculated based on the springs placed parallel and series combinations.

Table 1: Lateral strength values for failure mechanism

\begin{tabular}{|c|c|c|c|c|c|c|}
\hline Description & Wall 1 & Wall 2 & Wall 3 & Wall 4 & Wall 5 & Wall 6 \\
\hline Rocking Strength $\left(\mathrm{KN} / \mathrm{m}^{2}\right)$ & 63.11 & 30 & 16.327 & 9.51 & 40.33 & 23.70 \\
\hline Sliding Shear Strength $\left(\mathrm{KN} / \mathrm{m}^{2}\right)$ & 34.43 & 26.93 & 18.86 & 10.00 & 31.86 & 20.50 \\
\hline Governing Mechanism $\left(\mathrm{KN} / \mathrm{m}^{2}\right)$ & Shear & Shear & Rocking & Rocking & Shear & Shear \\
\hline
\end{tabular}

\subsection{Stress Interpretation}

In analyzing wall 1, compressive stress S11 and S22 values are less than the first step's permissible value of $294 \mathrm{KN} / \mathrm{m}^{2}$. But in the fourth step, the permissible value of stress is exceeded by S22 value at corners of the wall (Fig 1). The increase in stress is propagated in a diagonal direction towards the top corner from both sides. S12 value of wall was also less than the allowable shear stress of $149 \mathrm{KN} / \mathrm{m}^{2}$ up to step 4. But the value exceeds and found to be equal to $150.31 \mathrm{KN} / \mathrm{m}^{2}$ at step 5 . Hence, it can be concluded that the shear failure in-wall occurs in the wall instep 5. 
In analyzing wall 2, compressive stress S11 and S22 values are less than the permissible value of $294 \mathrm{KN} /$ $\mathrm{m}^{2}$ in the first step (Fig 2). In the step 3, the permissible value of stress is exceeded by S22 and S11 from step 5 at corners and around the openings of the walls. The increase in stress is propagated in a diagonal direction towards the top corner from openings. S12 value of wall was also less than the allowable shear stress of $149 \mathrm{KN} / \mathrm{m}^{2}$ up to step 3 . But the value exceeds and found to be equal to $186.6 \mathrm{KN} /$ $\mathrm{m}^{2}$ at step 4 at the top middle portion of the wall. Hence, it can be concluded that the shear failure in-wall occurs in the wall instep 3. Similar interpretations were carried out for all panels and the final results obtained are summarizes as follows:

For wall 3, stress was found maximum at the bottom line of the wall and first storey level. On further steps, stress was increased more rapidly at bottom ends than another portion of the wall (Fig 3). For wall 4, stress was found maximum at the wall's bottom line and first storey level (Fig 4). On further steps, stress was found to be increased more rapidly at bottom ends and around openings of the wall. For wall5, stress was found maximum at bottom ends of the wall and a storey level (Fig 5). The stress is almost equal along the horizontal line. On further analysis, stress was increased more rapidly at bottom ends than another portion of the wall. For wall 6 , stress was found maximum at the bottom of the wall and concentrated around the openings (Fig 6). On further analysis, stress was found to flow diagonally towards the top corners of the wall.

The above analysis concludes that masonry walls cannot withstand the applied loads in unreinforced condition. So, it is necessary to increase the capacity of the wall with the addition of reinforcement. Some of the sample analysis results in regular and shear stresses are shown in figures 1-6.Analysis of wall panels for reinforcement options of six different wall panels are designed and analyzed (Ghimire 2016) for different reinforcement options given below.

1. Unreinforced Masonry Wall
2. $12 \mathrm{~mm}$ dia. reinforcement bars vertically placed spaced at a distance of $1 \mathrm{~m}$.

3. Chicken wire mesh of $1 \mathrm{~m}$ width at both sides placed vertically at ends of the wall.

4. Chicken wire mesh applied at both sides of the wall throughout the wall panel.

5. $2 \mathrm{~mm}$ thick and $20 \mathrm{~cm}$ wide Four vertical strips of CFRP mesh applied at both sides of the wall.

6. $2 \mathrm{~mm}$ thick and $20 \mathrm{~cm}$ wide two horizontal and two vertical strips of CFRP mesh applied at both sides of the wall.

7. CFRP mesh applied at both sides of the wall throughout the wall panel.

\subsection{Analysis of Shear Failure}

The analysis has been carried out on a wall panel of the single-storey building with an aspect ratio of 0.6 , assuming the shear failure mechanism. Two parallel walls different in opening conditions are analyzed. The wall without opening is named Wall1 and the wall with a door as the opening is named as wall 2. The result obtained from the pushover analysis (ATC-40) of wall 1 is presented in Table 2. From Table 2, it is seen that there is a significant increase in load-carrying capacity of masonry wall panel also with different reinforcement options. There is an $84 \%$ increase in lateral load-carrying capacity of the wall in case 2, while it causes $44.73 \%$ of the wall displacement decrease. In Case 3, there is an increase in load-carrying capacity by $80.15 \%$ decreasing displacement by $38.98 \%$ while in Case 4, there is an increase in load-carrying capacity by $86.72 \%$ decreasing displacement of $39.94 \%$. In Case 5 , there is an increase in load-carrying capacity by $61.91 \%$ and decreases displacement by $15.01 \%$. In Case 6 , load carrying capacity is increased by $64.54 \%$, and displacement is decreased by $13.10 \%$ while in Case 7 , there is an increase in load-carrying capacity by $101.18 \%$ and decreases displacement by $23 \%$. The result obtained from pushover analysis is also presented in the graphical form, as shown in Fig. 7.

Table 2: Pushover analysis results for wall 1

\begin{tabular}{|ccccc|}
\hline $\begin{array}{c}\text { Reinforcement } \\
\text { Options }\end{array}$ & $\begin{array}{c}\text { Target Base Shear, } \\
\text { KN }\end{array}$ & Target Displacement, mm & $\begin{array}{c}\text { \% increase in Base } \\
\text { Shear }\end{array}$ & $\begin{array}{c}\text { \% decrease in Dis- } \\
\text { placement }\end{array}$ \\
\hline Case 1 & 63.92 & 3.13 & - & - \\
Case 2 & 117.62 & 1.73 & 84.00 & 44.73 \\
Case 3 & 115.16 & 1.91 & 80.15 & 38.98 \\
Case 4 & 119.36 & 1.88 & 86.72 & 39.94 \\
Case 5 & 103.50 & 2.66 & 61.91 & 15.01 \\
Case 6 & 105.18 & 2.72 & 64.54 & 13.10 \\
Case 7 & 128.60 & 2.41 & 101.18 & 23.00 \\
\hline
\end{tabular}




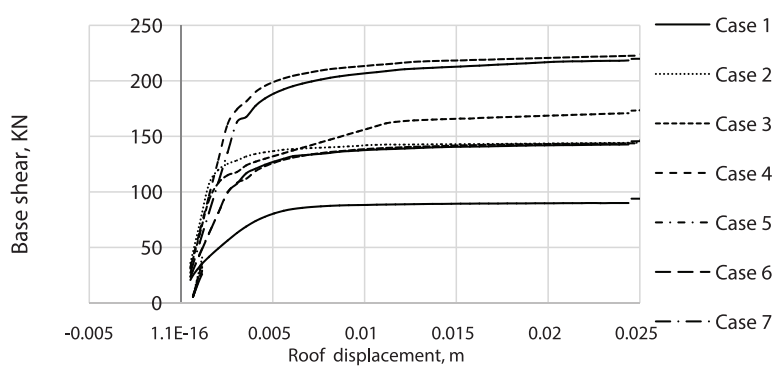

Fig. 7. Base shear vs roof displacement curves for wall1

The result obtained from the pushover analysis of wall 2 is also presented in the graphical form, as shown in Fig. 8. In Fig. 8, there is a significant increase in the masonry wall panel's load-carrying capacity with different reinforcement options. There is an $87.5 \%$ increase in the lateral load-carrying capacity of the wall and $12 \mathrm{~mm}$ diameter rebar at as pacing of $1 \mathrm{~m}$ while it causes $69.38 \%$ of the decrease in the wall's displacement. Chicken wire meshing of one-meter width applied to both sides at ends of the wall increases load-carrying capacity by $73.06 \%$ decreasing displacement by $38.54 \%$ while applying through the whole portion of the wall increases loadcarrying capacity by $127.66 \%$ decreasing displacement by $56.22 \%$. Application of horizontal and vertical CFRP strips of $20 \mathrm{~cm}$ width at each end of the wall increases loadcarrying capacity by $63.16 \%$ and decreases displacement by $23.49 \%$. Application of four vertical CFRP strips of $20 \mathrm{~cm}$ width both sides at the equal interval of the wall increases load-carrying capacity by $74.31 \%$ and decreases displacement by $32.04 \%$ while applying CFRP strips both sides throughout the wall increases load-carrying capacity by $132.68 \%$ and decreases displacement by $37.25 \%$.

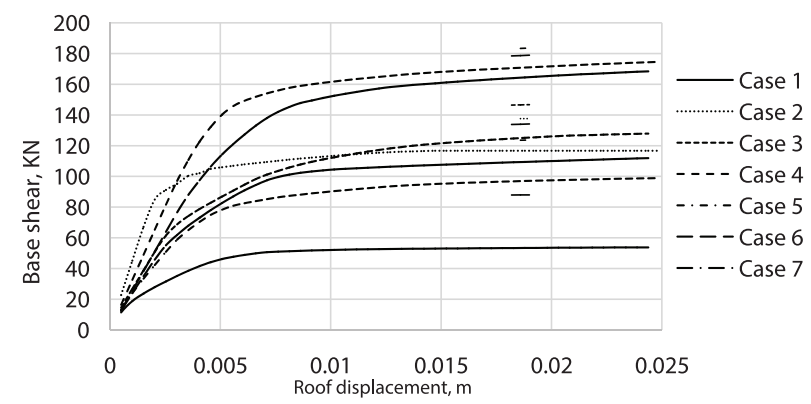

Fig. 8. Base shear vs roof displacement curves for wall 2

\subsection{Two Storey Wall for Rocking Mode}

The analysis has been carried out on a wall panel of a two-storey building with an aspect ratio of 1.71, assuming the rocking failure mechanism occurs. Two similar walls different in opening conditions are analyzed. The wall without opening is named Wall 3 and the wall with two windows on each floor as the opening is named as Wall 4. The result obtained from the pushover analysis of wall 3 is also presented in the graphical form, as shown in Fig. 9. From the Fig. 9 shows a maximum increase in the masonry wall panel's load-carrying capacity and different reinforcement options. There is a $172.6 \%$ increase in lateral load-carrying capacity of the wall in Case 2 while it causes $67.44 \%$ of the wall displacement decrease. Case 3 increases load-carrying capacity by $199.4 \%$ decreasing displacement by $48.84 \%$ while Case 4 increases loadcarrying capacity by $309.09 \%$ decreasing displacement by $53.49 \%$. In case 5 , load carrying capacity is increased by $146.68 \%$ and decreases displacement by $11.63 \%$. Case 6 increases load-carrying capacity by $154.91 \%$ and

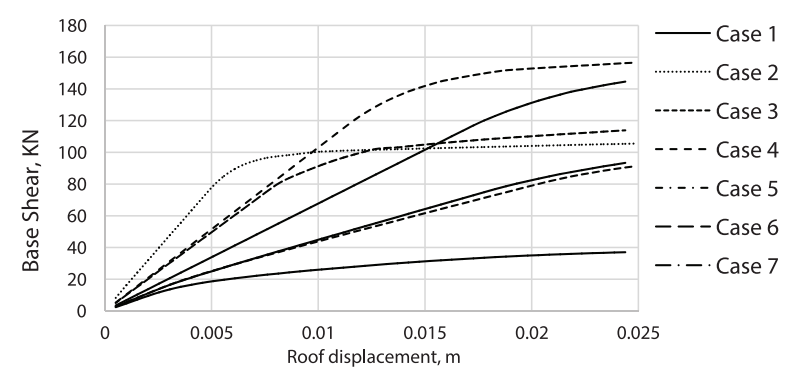

Fig. 9. Base shear vs roof displacement curves for wall 3

The result obtained from the pushover analysis of wall 4 is also presented in the graphical form, as shown in Fig.10. In Fig. 10, there is a maximum increase in the masonry wall panel's load-carrying capacity with different reinforcement options. There is a $131.05 \%$ increase in lateral load-carrying capacity of wall and $12 \mathrm{~mm}$ diameter rebar at as pacing of $1 \mathrm{~m}$ while it causes $61.22 \%$ of the decrease in the displacement of the wall. Chicken wire meshing of one-meter width applied to both sides at ends of the wall increases load-carrying capacity by $110.74 \%$ decreasing displacement by $30.61 \%$ while applying through the whole portion of the wall increases loadcarrying capacity by $194.75 \%$ decreasing displacement by $34.69 \%$. Application of horizontal and vertical CFRP strips of $20 \mathrm{~cm}$ width at each end of the wall increases loadcarrying capacity by $87.78 \%$ and decreases displacement by $8.16 \%$. Application of four vertical CFRP strips of $20 \mathrm{~cm}$ width both sides at the equal interval of the wall increases load-carrying capacity by $80.55 \%$ and decreases displacement by $0 \%$ while applying CFRP strips both sides throughout the wall increases load-carrying capacity by $156.28 \%$ and decreases displacement by $10.20 \%$. 


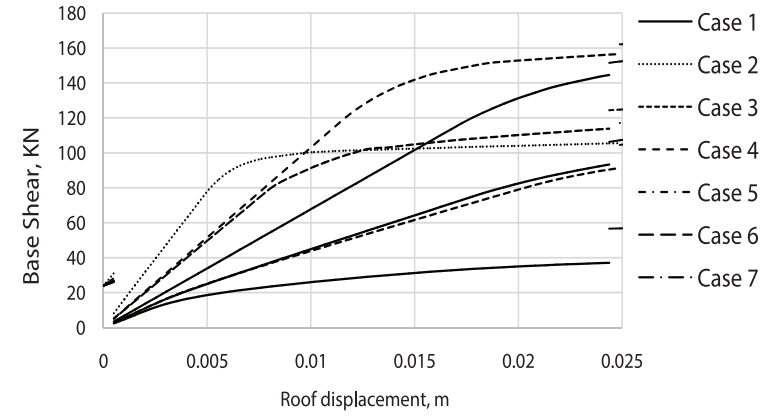

Fig. 10. Base shear vs roof displacement curves for Wall4

\subsection{Two Storey Wall for Shear Mode}

The analysis has been carried out on a wall panel of the two-storey building with an aspect ratio of 0.96 , assuming the shear failure mechanism. Two similar walls different in opening conditions are analyzed. The wall without opening is named Wall 5 and the wall with two windows on each floor as the opening is named as Wall 6. The result obtained from the pushover analysis of those wall panels is also presented in the graphical form, as shown in Fig. 11. From the Fig. 11 shows a significant increase in the masonry wall panel's load-carrying capacity and different reinforcement options. There is a $54.78 \%$ increase in the lateral load-carrying capacity of the wall in case 2 , while it causes $60.87 \%$ of the wall displacement decrease. Case 3 increases load-carrying capacity by $72.60 \%$ decreasing displacement by $47.83 \%$ while case 4 increases loadcarrying capacity by $135.64 \%$ decreasing displacement by $52.17 \%$. Case 5 increases load-carrying capacity by $53.26 \%$ and decreases displacement by $17.39 \%$. Case 6 increases load-carrying capacity by $54.37 \%$ and decreases displacement by $13.04 \%$ while applying CFRP strips to both sides throughout the wall increases load-carrying capacity by $132.92 \%$ and decreases displacement of $34.78 \%$.

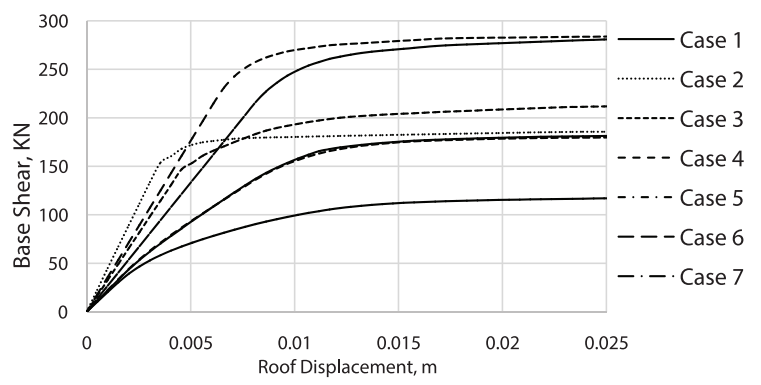

Fig. 11. Base shear vs roof displacement curves for wall5

The result obtained from pushover analysis of those wall panels is also presented in the graphical form as shown in Fig. 12 in Fig. 12, there is a significant increase in the load-carrying capacity of the masonry wall panel different reinforcement options. There is a $73.52 \%$ increase in the lateral load-carrying capacity of the wall and $12 \mathrm{~mm}$ diameter rebar at as pacing of $1 \mathrm{~m}$ while it causes $58.33 \%$ of the decrease in the wall's displacement. Chicken wire meshing of one-meter width applied to both sides at ends of the wall increases load-carrying capacity by $74.79 \%$ decreasing displacement by $16.67 \%$ while applying through the whole portion of the wall increases loadcarrying capacity by $147.04 \%$ decreasing displacement by $36.11 \%$. Application of horizontal and vertical CFRP strips of $20 \mathrm{~cm}$ width at each end of the wall increases loadcarrying capacity by $46.47 \%$ and decreases displacement by $16.67 \%$. Application of four vertical CFRP strips of $20 \mathrm{~cm}$ width both sides at the equal interval of the wall increases load-carrying capacity by $53.24 \%$ and decreases displacement by $11.11 \%$ while applying CFRP strips both sides throughout the wall increases load-carrying capacity by $135.29 \%$ and decreases displacement by $16.67 \%$. For detail calculation Ghimire (2016) is re referred. Better performance is because of confinement capacity of CFRP.

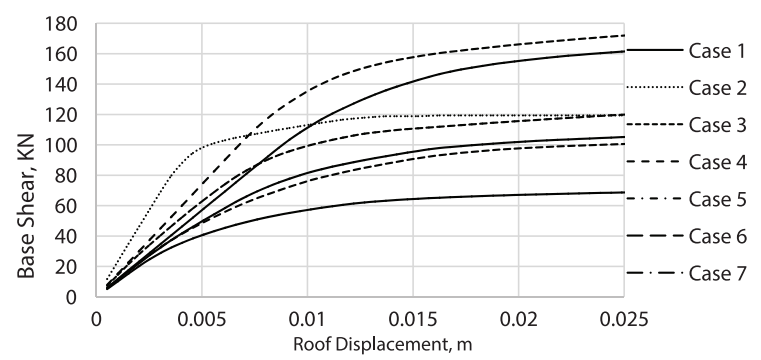

Fig. 12. Base shear vs roof displacement curves for wall 6

\section{CONCLUSION}

A simplified nonlinear layer model was developed by finite element method to represent the nonlinear behaviour of masonry wall. Different layers represented nonlinear properties of Masonry in different directions with different properties in each direction. The increase in performance of masonry wall after application of different skin retrofit options was evaluated. Six wall panels were checked for failure mechanism and analysed for shear and rocking failure mechanisms. The conclusions made after performing a nonlinear analysis of masonry walls after this study is carried out are as follows:

1. Skin retrofit options greatly influenced the loadcarrying capacity and displacement of the masonry wall.

2. Reinforcement bars of $12 \mathrm{~mm}$ diameter placed at a spacing of 1 meter significantly reduced the wall's displacement followed by chicken wire mesh applied throughout the wall. Application of CFRP did not play any vital role in decreasing the displacement of the wall. 
3. The wall's load-carrying capacity was significantly increased for CFRP mesh applied throughout the wall followed by chicken wire mesh throughout the wall, $12 \mathrm{~mm}$ reinforcement bars, chicken wire mesh of onemeter width at two ends $20 \mathrm{~cm}$ wide CFRP meshing around the ends of the wall.

4. Openings reduce load carrying capacity of the wall on shear by $30 \%$ in case of a single-storey, whereas $40 \%$ in case of the two-storey. Similarly, about $30 \%$ load carrying capacity is reduced on rocking failure mechanism.

5. Application of chicken wire mesh throughout the wall increases the load-carrying capacity of the wall such that almost same results were obtained for wall with and without opening in case of one storey wall in assumed shear failure mechanism.

Chicken wire can hold the wall very effectively and can be a very effective technique for retrofitting of low strength masonry walls with stone, brick and blocks.

\section{REFERENCES}

1. Abrams, D. \& N. Shah.1992. Cyclic Load Testing of Unreinforced Masonry Walls, Urbana-Champaign: s.n.

2. Ghimire, A. 2016. Numerical Modelling for Non-Linear Analysis of Masonry Walls, A Thesis submitted to Department of Civil Engineering, Thapathali Campus, IOE, TU Partial Fulfillment of the requirement of Master of Science in Earthquake Engineering.

3. ATC-40 1996. Seismic Evaluation and Retrofit of Concrete Buildings: Vol. 1. s.1.:Applied Technology Council, USA
4. Ghiassi, B., M. Soltani \& A.A. Tasnimi. 2004. A Simplified Model for Analysis of Unreinforced Masonry Shear Walls under Combined Axial, Shear and Flexural Loading.

5. Parajuli H.R. 2012. Determination of the Kathmandu World Heritage brick masonry buildings' mechanical properties, 15 WCEE, Lisbon. Portugal.

6. Parajuli H.R., J. Kiyono, H. Taniguchi. 2011. Structural Assessment of the Kathmandu World Heritage Buildings, Proceeding of 31st Conference on Earthquake Engineering, JSCE, Tokyo, Japan.

7. Lourenco, P.B. 1996. Computational Strategies for Masonry Structures., s.l: the Delft University of Technology, The Netherlands: Delft University Press.

8. Pandey, B.H. \& K. Meguro. 2004. Simulation of Brick Masonry Wall Behavior under In-plane Lateral Loading using Applied Element Method. 13th World Conference on Earthquake Engineering, Vancouver, Canada.

9. Pasticier, L., C. Amadio \& M. Fragiacomo. 2007. Nonlinear seismic analysis and vulnerability evaluation of a masonry building using the SAP2000 V.10 code. Earthquake Engineering and Structural Dynamics.

10. Yi, W.H., S.H. Oh \& J.H. Lee. 2004. Shear Capacity Assessment of Unreinforced Masonry Walls., 13th World Conference on Earthquake Engineering, Vancouver, B.C., Canada. 